\title{
PARÂMETROS OPERACIONAIS PARA IMPLANTAÇÃO DE UMA RECICLADORA DE PNEUS INSERVÍVEIS EM SANTA MARIA - RS
}

\section{Operational parameters for implantation of recycling of inservíveis tires in Santa Maria - RS}

\author{
Fabiano Viero Della Libera ${ }^{\#}$, Marco Antônio Zanini ${ }^{+}$, Marivane Vestena Rossato ${ }^{\text {\& }}$ \\ Jaqueline Carla Guse, Andréa Cristina Dorr* \\ Universidade Federal de Santa Maria - UFSM \\ ${ }^{\#}$ fabiano@via-rs.net, ${ }^{+}$mazanini@gmail.com, \\ \&marivavest@yahoo.com.br, *andreadoerr@yahoo.com.br
}

\section{Resumo}

O descarte inadequado de pneus inservíveis tem trazido malefícios para o ser humano. Neste contexto, surge a necessidade de conhecer alternativas como a implantação de uma recicladora de pneus inservíveis, a cidade proposta é Santa Maria, RS. O presente trabalho procurou evidenciar os parâmetros operacionais necessários, através do estudo exploratório, usando as técnicas de análise documental e de conteúdo. Apresentam-se os custos para aquisição de máquinas, instalações e mão-de-obra mensal. A produção é dividida em borracha e aço, sendo que o aço tem comprador certo. A recicladora apresenta-se como uma alternativa viável por apresentar lucro e trazer benefícios ambientais.

Palavras-chave: Pneu Inservível, Reciclagem, Parâmetros Operacionais

\section{Abstract}

The inadequate discarding of inservíveis tires has brought curses it human being. In this context, the necessity appears to know alternatives as the implantation of recicladora of inserviveis tires, the city proposal is Saint Maria, RS. The present work looked for to evidence the necessary operational parameters through the exploratório study, using the techniques of documentary analysis and content. One presents, the costs for acquisition of machines, installations and hand of monthly workmanship. The production is divided in rubber and steel, being that the steel has certain purchaser. The recicladora is presented as viable alternative for presenting profit and bringing ambient benefits.

Word-key: Operational Inservível tire, Recycling, Parameters

\section{INTRODUÇÃO}

É notável o aumento da produção e utilização de automóveis a nível mundial, e o número de pneus descartados, consequentemente, aumentou da mesma forma. Nesse particular, o que pode ser verificado também é uma elevação da disposição desse material em lixões, aterros 
sanitários e a céu aberto, atraindo vetores transmissores de doenças, além de causar uma imagem negativa e nociva ao meio ambiente, traduzida em poluição.

Diante deste fato, ressalta-se que existem falhas no mecanismo de mercado, no que se relaciona ao campo ambiental, uma vez que aqueles resíduos não são facilmente decompostos. Cerca de 600 anos seriam necessários para a assimilação dos pneus pelo meio ambiente, o que torna imperativo a adoção de medidas que visem oferecer alternativas para uma destinação ou disposição adequada dos pneus inservíveis e, que ao mesmo tempo, sejam alternativas viáveis economicamente. Salienta-se que o meio ambiente possui uma capacidade para assimilar resíduos, contudo quando o volume de resíduos lançado for superior a essa capacidade, o meio ambiente torna-se poluído.

A reciclagem de pneus apresenta-se como uma alternativa atraente, na medida em que tira de circulação pneus inservíveis e também oferece uma destinação correta. Cabe enfatizar que várias são as formas de aproveitamento dos pneus descartados. Dentre elas destaca-se o uso na pavimentação asfáltica, reduzindo o uso do petróleo e aumentando a resistência e aderência do asfalto.

No município de Santa Maria - RS, ainda não há uma legislação que regule a questão da destinação dos pneus inservíveis, os quais se apresentam como um sério problema a ser resolvido. Existem propostas de criação de um local para depósito dos pneus por parte da Prefeitura Municipal de Santa Maria, porém ainda não seria a solução completa, pois se faz necessário medidas que visem a destinação adequada e reaproveitamento da matéria-prima oriunda dos pneus inservíveis. Como são poucas as fábricas atuantes nesta área não se conhece quais são os parâmetros operacionais e quais os gastos envolvidos em sua implantação.

Nesse contexto, e considerando a reciclagem como uma alternativa à destinação dos pneus inservíveis, o estudo realizado teve por preocupação construir e discutir parâmetros operacionais necessários para a instalação de uma usina de reciclagem de pneus inservíveis no município de Santa Maria - RS.

\section{PROCEDIMENTOS METODOLÓGICOS}

A presente pesquisa caracteriza-se como sendo um estudo de natureza exploratória, tendo como finalidade proporcionar uma maior familiaridade com os processos de reciclagem de pneus inservíveis, bem como a construção e proposição dos parâmetros operacionais para implantação de uma empresa de reciclagem para este tipo de resíduo sólido, em Santa Maria-RS.

No entendimento de Silva (2003) este tipo de pesquisa é realizado em área na qual há pouco conhecimento acumulado sobre o assunto.

A classificação da pesquisa enseja o uso de técnicas, também denominadas como métodos de pesquisa. E, a partir dos métodos de pesquisas existentes, procurou-se utilizar-se daqueles que melhor auxiliassem na busca pela construção dos parâmetros operacionais.

O levantamento dos gastos envolvidos à implantação da empresa foi realizado através do contato com empresas do ramo e a pesquisa de mercado proporcionou o conhecimento do possível comprador deste material reciclado e a sua demanda. Com o método de análise de documentos foram levantados os custos das licenças e dos incentivos fiscais, do objeto em questão.

Para efeito da construção da metodologia proposta, os valores obtidos junto à empresa parâmetro, em $\mathrm{R} \$$ (reais), foram convertidos para a moeda dólar(US\$), em virtude da sua adoção como moeda padrão. O dólar utilizado foi o Comercial Médio para Venda, do período, cujos 


\section{REGEXALSM}

Rev. Elet. em Gestão, Educação e Tecnologia Ambiental

(e-ISSN: 2236-1170)

valores foram extraídos do site Portal Brasil. Outrossim, informa-se que nessa moeda a vírgula (,) é utilizada nas unidades de milhar. Já, o ponto (.) é utilizado para a unidade de dezena.

\section{REALIDADE E INICIATIVAS COM RELAÇÃO À PROBLEMÁTICA DOS PNEUS}

Como forma de amenizar o impacto ambiental causado pelo destino inadequado dos pneus inservíveis, e devido à consciência da responsabilidade ecológica de cada indivíduo e entidade, ou ainda devido à ineficácia dos responsáveis legais, algumas prefeituras e empresas estão tomando atitudes no sentido de dar uma destinação ambientalmente correta aos resíduos pneumáticos.

\subsubsection{O problema em Santa Maria}

A questão dos pneus inservíveis em Santa Maria ainda carece de um estudo adequado que considere a forma mais correta e econômica de destinação. A secretaria de proteção ambiental do município reconhece o problema, mas ainda não desenvolveu nenhuma ação que fosse efetiva. Como citado, na apresentação deste estudo, a administração municipal teve a idéia de criar um local para armazenar os pneus inservíveis, porém ainda não tomou nenhuma iniciativa até porque, a responsabilidade pela coleta e destinação adequada é dos fabricantes de pneus, conforme estabelece a Resolução do CONAMA no 258/99. Porém, conforme informações obtidas junto a empresários da cidade isto não acontece em Santa Maria - RS.

As empresas revendedoras de pneus da cidade procuram livrar-se dos pneus doando para catadores e carroceiros. Alguns destes vendem os pneus para uma fábrica localizada na cidade, que efetua o corte. Após o procedimento de corte, envia para outra cidade próxima a Porto Alegre para ser reciclado. Já a empresa Casa dos Pneus informou que os pneus inservíveis acumulados em sua empresa são doados para carroceiros, que vendem para uma borracharia da cidade para a fabricação de tubos, semelhantes aos tubos de concreto, usados no saneamento da cidade.

A empresa GP Pneus, conforme informações prestadas, doa os pneus para uma pessoa da cidade de Santa Maria, que utiliza-os como matéria-prima na fabricação de arruelas de borracha para fixação de coberturas de brasilite. Já na empresa Mademax Pneus, os pneus velhos são doados para quem tiver o interesse em levar. Diz ele, que geralmente faz a doação para uma pessoa que usa na fabricação de lastros de borracha para cama, e outra parte para um camioneiro que transporta para reciclar em outra cidade. Por sua vez, a empresa Tchê Pneus não possui nenhuma forma de eliminação dos resíduos, por isso envia para o Estado de Santa Catarina, onde são reciclados. Para isso, conforme informações levantadas, a empresa paga uma transportadora.

Todas essas medidas adotadas pelos empresários de Santa Maria são desenvolvidas como alternativa para a falta de uma política organizada de destinação adequada, de forma constante e confiável.

\subsubsection{Iniciativa de outras cidades gaúchas}

A problemática do pneu inservível se estende por praticamente todas as cidades. Muitas delas, por não ter uma alternativa melhor, acabam pagando a transportadoras para levar estes resíduos até centros de reciclagem. Exemplo disto ocorre no município de Eldorado do Sul - RS. A iniciativa da prefeitura de recolher os pneus velhos nas borracharias do município para então enviar para a empresa Cimpor, na cidade de Nova Santa Rita - RS, como forma de eliminar 
possíveis focos do mosquito transmissor da dengue, foi divulgada em sua página na internet. 0 custo do transporte ficou a cargo da prefeitura municipal.

Na cidade de Vacaria - RS, a administração municipal, através do Departamento Municipal de Limpeza Urbana, divulgou através do site da prefeitura municipal, o envio de uma carga de pneus inservíveis para o município de Curitiba - PR. Este transporte foi feito pela Associação Nacional de Importadores de Pneumáticos (ANIP) e, como no caso de Eldorado do Sul, esta iniciativa tem como objetivo limpar a cidade e extinguir focos do mosquito da dengue.

A coleta de pneus velhos ocorre de forma sistemática na cidade de São Lourenço do Sul RS, conforme informa o site da prefeitura municipal. Nesta cidade, existe um calendário de coleta, organizado pela prefeitura em parceria com a Empresa de Reaproveitamento de Pneus (ReciclANIP), empresa esta sem fins lucrativos, ligada a ANIP, organizada em 2007, e criada pelos fabricantes de pneus novos Bridgestone Firestone, Goodyear, Michelin e Pirelli, cujo foco principal é a coleta e destinação de pneus inservíveis no Brasil de forma mais estruturada. A entrega dos pneus nesta cidade é feita pelos proprietários no ponto de coleta. Após, o material é enviado para a Associação Reciclanip, que encaminha para empresas de trituração ou destinação final, que sejam ambientalmente corretas.

É do conhecimento de todos que os pneus inservíveis, sem a devida destinação, tornam-se um problema e, mesmo não sendo de responsabilidade das prefeituras municipais, estas acabam tendo que arcar com os custos de transporte ou mesmo com o serviço de administrar tais resíduos.

\subsubsection{Iniciativa de empresas privadas}

Empresas privadas do setor de pneumáticos também estão tomando iniciativas no sentido de cumprirem o seu papel na responsabilidade ambiental. Segundo estudo realizado por Andrade (2008), da Universidade Federal de Santa Catarina, que versa sobre os pneus inservíveis, três empresas se destacam por suas iniciativas: a Rede Dpaschoal (Goodyear), a Bridgestone Firestone e Pirelli do Brasil.

A Rede Dpaschoal em parceria com a fabricante Goodyear mantém um processo de coleta e destinação dos pneus inservíveis em mais de 180 de suas lojas espalhadas no Brasil, com a finalidade de incentivar e mobilizar funcionários, consumidores e população em relação ao destino ambientalmente correto dos pneus inservíveis.

Além deste projeto, a Dpaschoal fornece seus pneus usados à empresa Goóc, uma fabricante de calçados e acessórios feitos a partir da borracha reciclada de pneus. Esta, já reciclou mais de um milhão de pneus inservíveis e a empresa prevê comercializar 210 milhões de pares de sandálias feitas de pneu reciclado até 2014 no Brasil.

A ação da empresa Bridgestone Firestone envolve a picotagem dos pneus refugados pelo seu processo produtivo e os pneus inservíveis na própria fábrica, os quais, posteriormente, são encaminhados para o processo de reciclagem.

Essa empresa participou de várias ações isoladas. Dentre elas, em 2003, em parceria com a ANIP, da campanha de recolhimento de pneus inservíveis intitulada: Pneus não nasceram para ficar parado. Devolva para reciclar. Este projeto consistia na entrega de pneus nas revendedoras Brigestone por parte dos consumidores que, em troca desta ação, recebiam bonés e ingressos para corridas de Fórmula Truck. A empresa conseguiu recolher cerca de 55 mil pneus inservíveis com esta iniciativa. 


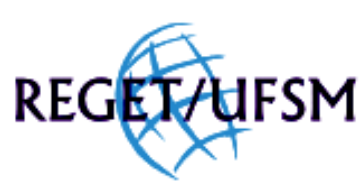

Libera et al., v(6), no 6, p. $1049-1065,2012$.

Em 2006, no lançamento de uma linha de pneus para caminhonetes chamadas Destination, os consumidores eram incentivados a deixar nas lojas os pneus descartados após a troca, sendo concedido um bônus de $\mathrm{R} \$ 25,00$ (vinte e cinco reais) por pneu. Estes eram enviados para os ecopontos através da logística da empresa.

Além disso, a Brigestone, Firestone, Goodyear, Michelin e Pirelli, em conjunto com a ANIP, fundaram em março de 2007, a RECICLANIP, uma entidade que se responsabilizará pelo processo de coleta, transporte e envio da carga de pneus inservíveis dos pontos de coleta até as empresas de trituração ou destinação final. Para isso, os fabricantes pretendem investir aproximadamente $\mathrm{R} \$ 50$ milhões na reciclagem de pneus.

A Pirelli divulga, em sua revista Pirelli Club Truck, a importância da correta destinação dos pneus inservíveis, além de publicar dados a respeito de empresas reconhecidas e cadastradas junto a ANIP para coleta, transporte e trituração dos inservíveis, alertando para a possibilidade deste material ser depositado nos ecopontos mantidos pela ANIP em várias cidades do país. A Pirelli também se dispõe a coletar pneus inservíveis através de seus pontos de coleta chamados Truck Center Pirelli.

\section{Alternativas de destino aos pneus inservíveis}

\subsection{A atividade da reciclagem}

De acordo com informações publicadas pela Compam (2007), reciclagem é um conjunto de técnicas que tem por finalidade aproveitar os detritos e reutilizá-los no ciclo de produção de que saíram. É o resultado de uma série de atividades, pelas quais materiais que se tornariam lixo, ou estão no lixo, são desviados, coletados, separados e processados para serem usados como matéria-prima na manufatura de novos produtos.

O retorno da matéria-prima ao ciclo de produção é denominado reciclagem, embora o termo já venha sendo utilizado popularmente para designar o conjunto de operações envolvidas. O vocábulo surgiu na década de 1970, quando as preocupações ambientais passaram a ser tratadas com maior rigor, especialmente após o primeiro choque do petróleo, quando reciclar ganhou importância estratégica. As indústrias recicladoras são também chamadas secundárias, por processarem matéria-prima de recuperação. Na maior parte dos processos, o produto reciclado é completamente diferente do produto inicial.

\subsection{Programa de coleta e destinação - ANIP}

Segundo informações divulgadas pela ANIP (Associação Nacional da Indústria de Pneumáticos - 2008), desde 1999 esta associação vem desenvolvendo o Programa de coleta e destinação de pneus inservíveis, considerado hoje o maior programa de responsabilidade pósconsumo da indústria brasileira. Para o sucesso do programa, a Associação promove parcerias com prefeituras de todas as regiões do Brasil. Atualmente, 237 municípios já aderiram ao Programa e implantaram centros de recepção de pneus inservíveis - os chamados "Ecopontos".

No processo de coleta, a ANIP é responsável por toda a logística do Programa, realizando o transporte dos pneus desde os "Ecopontos" até as empresas de trituração, de onde serão encaminhados para destinação final. 


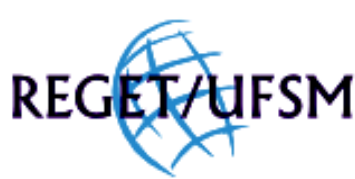

Libera et al., v(6), no 6, p. $1049-1065,2012$.

Os ecopontos são os locais de recepção dos pneus inservíveis, possibilitando a destinação ambientalmente correta desses objetos. A coleta pode ser feita pelo serviço de limpeza pública do município e por borracheiros, mecânicos e sucateiros, esses parceiros podem levar os pneus inservíveis coletados a qualquer um dos ecopontos espalhados em diversos estados do país, incluindo a possibilidade desses pneus serem levados diretamente às empresas de trituração ou picotagem - os chamados centros de recepção e picotagem - sem passar pelos ecopontos.

A ANIP implantou o programa de coleta e destinação de pneus inservíveis, que são aqueles que não podem mais rodar em veículos automotivos.

\subsection{Alternativas para o aproveitamento dos pneus}

A questão do reaproveitamento dos pneus é tema em discussão junto a Universidade de São Paulo - USP, que apresenta a questão dos pneus como controversa. Empregados e produzidos em larga escala na indústria automobilística, são um dos marcos da poluição urbana e, em muitos casos, servem como criadouro para os mosquitos da dengue.

Passerotti (2003), em sua dissertação de mestrado, concluiu que são quatro as alternativas mais viáveis em termos de aproveitamento dos pneus inservíveis: reforma (recauchutagem), Pirólise (sistema Petrobrás-six), utilização como combustível em fornos de cimento e utilização como componente em asfalto.

Andrade (2007), em seu trabalho de conclusão no Curso de Ciências Econômicas da Universidade Federal de Santa Catarina, afirma que os maiores investimentos em tecnologia ficam por conta das cimenteiras na adaptação de seus fornos para a queima de pneus inservíveis, uma vez que ao receber este material estas fábricas têm duas vantagens - diminuem custos com energia e são remuneradas pelos fabricantes de pneus para destruir este material em seus fornos.

Além do uso nas cimenteiras, Andrade (2007), destaca o uso dos pneus inservíveis em diversas outras formas, tanto na sua forma inteira quanto picado ou com seus componentes separados. Na engenharia civil, os pneus podem ser bastante usados. As aplicações mais comuns são: em materiais de enchimento leve; drenagem em campo séptico; aterro em estradas; suporte de base de estrada. Sistema de drenagem de gases em aterros sanitários; estabilizadores de encostas; controle de erosão; diques; barragens; isolante térmico e acústico; drenagem em aterro sanitário, aditivos para pavimentos asfálticos; pistas esportivas; cobertura de parques infantis; concretos leves, entre outros. Já na sua forma inteira estão relacionados a projetos de obras de drenagens, onde os pneus são unidos em módulos de aproximadamente 15 pneus, que formam um tubo em substituição aos bueiros, apresentando desempenho aceitável; limitação do território esportivo, com pneus formando muros de limitação para a prática de esportes automotivos de alta velocidade, também em pistas de corridas de cavalo; parques infantis e playground, onde são utilizados como brinquedos ou mesmo como amortecedores de impacto dos brinquedos; construção de barragens; recifes artificiais; em muros de arrimo e contenção; contenção da erosão do solo; enchimento de aterros; reforço de aterros; compostagem; vasos e móveis feitos com pneus; entre outros.

\subsection{Legislação}

No que concerne à legislação sobre a questão ambiental dos pneus inservíveis, mencionase aqui a Resolução do CONAMA no. 258/99.

A Resolução do CONAMA no. 258 de 26/08/1999 determina que as empresas fabricantes e importadoras de pneus ficam obrigadas a coletar e dar a destinação final, ambientalmente 
adequada, aos pneus descartados no território nacional. A partir de 01/01/2002 para cada quatro pneus novos colocados no mercado nacional, um pneu descartado seria recolhido. Em 2003 seriam recolhidos dois pneus descartados para cada quatro novos pneus. Até que em 2005 seriam recolhidos cinco pneus descartados para cada quatro novos pneus produzidos ou importados. É importante salientar que a partir de 02/12/1999 está proibida a disposição de pneus descartados em aterros sanitários, mares, rios, lagos ou riachos, terrenos baldios ou alagadiços e a queima a céu aberto.

Destaca-se que o órgão que tem a competência para o controle, fiscalização e normatização dos pneumáticos é o IBAMA (Instituto Brasileiro do Meio Ambiente e dos Recursos Naturais Renováveis).

\section{Resultados}

Os parâmetros operacionais foram construídos e propostos a partir de dados obtidos junto à empresa Dragon Importadora \& Exportadora, fornecedora de máquinas para reciclagem de pneus inservíveis.

\subsection{A organização parâmetro}

A Dragon Importação \& Exportação de Produtos Manufaturados Ltda. iniciou suas atividades em 1988, na cidade de Curitiba-PR. Esta organização fornece máquinas de reciclagem e suporte técnico para implantação de indústrias de beneficiamento de resíduos sólidos. Assim, serviu de base para a construção dos parâmetros operacionais relativos às máquinas e equipamentos utilizados na reciclagem do pneu.

\subsection{A estrutura operacional}

A partir dos dados obtidos junto a Dragon Importação \& Exportação, projetou-se à estrutura operacional da recicladora de pneus.

a) O sistema de reciclagem de pneus

O funcionamento do equipamento fornecido pela empresa Dragon Importação \& Exportação necessita de cinco a seis operadores de máquinas por turno, sendo composto por um mecanismo eletrônico de controle automático de alimentação, com excelente segurança, processando de 1600 a $2000 \mathrm{~kg} / \mathrm{h}$ de pneus (dependendo do tipo de pneu, incluindo os componentes borracha, aço e nylon). A produção da recicladora é demonstrada no Quadro 1.

\begin{tabular}{|l|c|c|}
\hline & Pneu de caminhão & Outro tipo de pneus \\
\hline $\begin{array}{l}\text { Migalha de borracha, } \\
\text { Inferior a 6mm }\end{array}$ & 1200 a $1600 \mathrm{~kg} / \mathrm{h}$ & 800 a $1200 \mathrm{~kg} / \mathrm{h}$ \\
\hline Fragmento de aço & 300 a $500 \mathrm{~kg} / \mathrm{h}$ & 150 a $200 \mathrm{~kg} / \mathrm{h}$ \\
\hline Nylon e outras sujeiras & 20 a $500 \mathrm{~kg} / \mathrm{h}$ (depende do conteúdo do pneu) \\
\hline
\end{tabular}

Quadro 1 - Demonstrativo da produção por hora. 
b) As despesas de instalação do maquinário

A instalação contará com uma equipe de quatro técnicos e dois engenheiros, ficando a cargo do comprador a alimentação, hospedagem, transporte e passagem. O total de despesas diário com instaladores e engenheiros é de US\$168,00. Estes valores foram levantados junto aos hotéis Ravas e Continental de Santa Maria - RS, considerando os custos locais. O número estimado de dias necessários para a instalação é de aproximadamente 20 dias. O custo das passagens de ida e volta, entre Santa Maria - RS e Curitiba - PR é de US\$ 276,51, segundo Via Mundi turismo.

c) Os custos relativos a registro de imóveis

O custo de registro do terreno, escrituração e ITBI (Imposto de Transmissão de Bens Intervivos) são de, respectivamente, US\$ 84,00 (oitenta e quatro dólares), US\$ 126,40 (cento e vinte seis dólares e quarenta cents) e US\$218,19 (duzentos e dezoito dólares e dezenove cents). 0 ITBI corresponde a $2,15 \%$ do valor do imóvel.

Esses valores foram obtidos junto ao Cartório Registro de Imóveis e no 10 Tabelionato Santa Maria-RS.

d) O custo do projeto

A estrutura básica do projeto deve contar com um terreno correspondente a uma área de $10.000 \mathrm{~m}^{2}$ (equivalente a 50 por 200 metros). O terreno determinado para a instalação está localizado no Distrito Industrial de Santa Maria - RS.

O custo do local de instalação do maquinário e consequentemente onde será processada a matéria-prima foi calculado pelo CUB do galpão industrial, compreendendo a $4320 \mathrm{~m}^{3}$ (30 metros de comprimentos, 24 metros de largura e 6 metros de altura).

O mobiliário do escritório é composto por mesas, cadeiras, armários, computadores, fax, condicionador de ar, impressora, entre outros móveis. E, o refeitório contém mesas, cadeiras, refrigerador, fogão, etc.

O valor referente ao sistema de segurança corresponde a US\$332.94, obtidos junto à empresa SOS Monitoramento.

O Quadro 2 sintetiza a área demandada para as referidas instalações, o mobiliário para o escritório, o refeitório e os equipamentos do sistema de segurança, bem como os valores a serem investidos.

\begin{tabular}{|c|c|c|}
\hline Imóveis e Móveis & Área & Valor (em US\$) \\
\hline Terreno & $10.000 \mathrm{~m}^{2}$ & $10,148.37$ \\
\hline Galpão industrial & $4.320 \mathrm{~m}^{3}$ & $160,763.87$ \\
\hline Escritório & $80 \mathrm{~m}^{2}$ & $34,827.79$ \\
\hline Vestiário e sanitários & $60 \mathrm{~m}^{2}$ & $20,172.50$ \\
\hline Refeitório & $36 \mathrm{~m}^{2}$ & $6,867.64$ \\
\hline Mobiliário escritório & & $1,270.98$ \\
\hline Mobiliário refeitório & & 332.94 \\
\hline Sistema de alarme & & $278,004.92$ \\
\hline Total & & \\
\hline
\end{tabular}

Quadro 2 - Custo do projeto (em US\$). 
e) Máquinas e equipamentos

Os custos com máquinas e equipamentos de reciclagem, importam em US\$ 2,254,000.00. Com uma empilhadeira com capacidade para 2,5 toneladas, importa em US\$29,000.00, que se faz necessária ao processo de reciclagem, somando um total de US\$2,283,000.00.

\section{f) Licenciamento}

Os custos de licenciamento junto à Fundação Estadual de Proteção Ambiental (FEPAM), somam US\$ 4,960.00 (quatro mil novecentos e sessenta dólares).

Para que uma indústria de reciclagem de resíduos sólidos possa operar, é necessária a obtenção da licença prévia, de instalação e de operação. Este valor se refere a uma indústria considerada de potencial poluidor médio, ou seja, que tenha uma produção entre cento e cinqüenta a três mil metros cúbicos.

\section{g) Incentivos municipais}

O município de Santa Maria possui uma política de atração de investimentos regulamentada através da Lei Complementar no 037/06. Denominada Empreende Santa Maria, estabelece normas e procedimentos para a concessão de incentivos municipais que venham promover o Desenvolvimento Econômico de Santa Maria. De até 9\% do incremento mensal de faturamento bruto, limitado a 75\% do ICMS incremental mensal devido Serviço de Qualquer Natureza - ISSQN - e concessão de incentivos econômicos, como apoio a infra-estrutura (serviços de terraplanagem, topografia, entre outros), concessão de áreas, para instalação, em regime de comodato e auxílio em locação de área física.

Esses incentivos não foram considerados para a instalação e operação da recicladora em questão, porém foram mencionadas para que, de conhecimento da existência, a proposta de empreendimento possa estar se beneficiando, no caso de expansão da atividade e/ou novas aquisições.

\section{h) Incentivos Estaduais}

O Estado do Rio Grande do Sul disponibiliza um programa de atração de investimentos industriais através de concessão de incentivos pelo Programa Fundo Operação Empresa do Estado do Rio Grande do Sul (FUNDOPEN). Esse programa consiste em financiar parcela de até $75 \%$ do ICMS incremental devido mensalmente pelo estabelecimento incentivado. O ICMS incremental é todo aquele gerado por uma nova unidade industrial ou pelo aumento de uma unidade industrial já estabelecida.

Além do financiamento de parte do ICMS é oferecido o incentivo adicional denominado Programa de Harmonização do Desenvolvimento Industrial (INTEGRAR/RS), com o objetivo de promover a descentralização industrial. Esse incentivo, na prática, consiste na concessão de um percentual de abatimento incidente sobre o valor de cada parcela de amortização do financiamento do FUNDOPEM/RS, inclusive encargos, caso seja paga até a data de vencimento. Pelo fato do município de Santa Maria estar localizado na metade sul do Rio Grande do Sul, denominada a região menos industrializada, esse abatimento para as empresas que vierem aqui se instalar é na ordem de 51\%, determinado pelo indicador INTEGRAR/IDESE (Programa de Harmonização do Desenvolvimento Industrial - Indicadores de Desenvolvimento SócioEconômico), que consta na Resolução Normativa no. 02/2003 - FUNDOPEM/RS e INTEGRAR/RS. 


\section{i) Financiamento}

As instituições de crédito do Sistema Financeiro Estadual oferecem apoio creditício, de longo prazo, para financiar a realização de investimentos de projetos. Estas instituições de crédito são agentes do Banco Nacional de Desenvolvimento Econômico e Social (BNDES), concedendo crédito para financiamento de máquinas e equipamentos (FINAME).

j) Matéria-prima

A matéria-prima para a produção de migalhas de borracha será obtida através de parcerias firmadas com prefeituras, com a entrega direta pelos usuários dos pneus ou ainda com a possibilidade de obtenção através de contrato com a Associação Nacional de Importadores de Pneumáticos (ANIP).

k) O rendimento da mão-de-obra

A partir de uma produção mensal de 255,55 toneladas de migalhas e 68,73 toneladas de fragmentos de aço, numa jornada de 44 horas semanais, com 6 funcionários diretamente envolvidos no processo produtivo, obtém-se um rendimento médio por funcionário/hora de 220 $\mathrm{kg}$ de migalha de pneu e 59,16 kg de fragmento de aço.

I) Salário médio mensal

O salário médio mensal pago pela organização aos operários, motorista e ao funcionário administrativo é de US\$ 271.00 (duzentos e setenta e um dólares). Já a secretária recebe US\$ 406.00 (quatrocentos e seis dólares) e o gerente (proprietário) recebe como pró-labore mensal US\$ 1,084.00 (um mil e oitenta e quatro dólares). Os salários em questão foram calculados com base no salário mínimo regional de maior valor. Sendo diferenciados os salários da secretária e do gerente devido a responsabilidades associadas as suas funções. Os encargos incidentes sobre estes salários correspondem a 50,73\%. E, ao profissional da área contábil, US\$177.00 (cento e setenta e sete dólares), a título de honorários profissionais.

m) Despesas de telefone, água e energia elétrica

As despesas (média/mensal) de ligações telefônicas importam em US\$ 810.00 (oitocentos e dez dólares). Já, a média mensal de água gira em torno de US\$ 115.00 (cento e quinze dólares), e a despesas com energia elétrica é de US\$ 15,351.02 (quinze mil trezentos e cinqüenta e um dólar e sessenta e dois cents) sendo que US\$ 65.00 (sessenta e cinco dólares) correspondente à parte administrativa. A energia elétrica mensal gasta pelo sistema de reciclagem é de $88.475,20 \mathrm{~kW}$ (457kw x 193,6 horas mensais - 44h semanais, 22 dias mensais). Esses valores foram obtidos através de uma empresa que atua neste ramo, mas que não quis ser identificada.

n) Despesas com segurança

O gasto mensal com segurança é de US\$ 52.11, referentes ao serviço de vigilância monitorada, prestado pela empresa SOS Monitoramento.

o) Custos relativos à legalização da empresa

Para legalizar a empresa são necessárias as seguintes inscrições:

- Registro na Junta Comercial (US\$ 43.46)

- Registro na Secretaria da receita federal - CNPJ (sem custos)

- Registro na Secretaria de Estado da Fazenda (sem custos)

- Registro no INSS (sem custos) 
- Registro na Prefeitura do Município - Alvará (US\$ 228.60), valor correspondente à área construída de 300 a $1000 \mathrm{~m}^{2}$.

\subsubsection{Operacionalização dos dados}

A partir dos dados e informações coletados foram construídos os demonstrativos de resultado e patrimonial.

\subsubsection{Estrutura de resultado}

Segundo a Dragon, o principal produto obtido do pneu, a migalha de borracha, pode ser vendido por duzentos e oitenta e nove dólares e cinqüenta e dois cents, (este preço varia de acordo com sua pureza). Os fragmentos de aço retirados dos pneus possuem mercado certo na cidade de Santa Maria-RS, pois foi levantado comprador, a Sucata Santa Maria. A tonelada desses fragmentos seria vendida a US\$104.22 (cento e quatro dólares e vinte e dois cents).

A matéria-prima é obtida de forma gratuita, pois a responsabilidade por uma destinação correta deste resíduo é dos fabricantes. Já a mão-de-obra direta refere-se a oito funcionários envolvidos na produção.

O sistema de reciclagem de pneus possui uma grande quantidade de lâminas, (cuja finalidade é reduzir os pneus a pequenas partículas) que podem ser afiadas determinado número de vezes. Após atingirem certa capacidade de processamento, precisam ser substituídas. A depreciação das máquinas e equipamentos foi estimada em $10 \%$ ao ano, já a empilhadeira em $25 \%$ ao ano (conforme - Instrução Normativa Secretária Receita Federal no 72/84).

Numa jornada de trabalho de cento e noventa e três horas mensais, a produção média obtida de migalhas de borracha é de duzentos e cinquenta e cinco toneladas, e sessenta e oito toneladas para os fragmentos de aço. Estes dados podem ser mais bem visualizados no Quadro 3.

\begin{tabular}{|l|r|}
\hline \multicolumn{1}{|c|}{ Variáveis } & \multicolumn{1}{|c|}{ Valores } \\
\hline 1) Preço Médio de Venda da Migalha de Borracha & US\$289.52/ton ada \\
\hline 2) Preço Médio de Venda dos Fragmentos de Aço & US\$104.22/ton ada \\
\hline 3) Custo da Matéria Prima & US\$0.00 \\
\hline 4) Custo da Mão-de-Obra Direta (com encargos) & US\$3,255.76 \\
\hline 5) Custo da Energia Elétrica & US\$15,351.62 \\
\hline 6) Custo de Reposição de Lâminas & US\$6,658.33 \\
\hline 7) Depreciação de Máquinas e Equipamentos & US\$18,783.33 \\
\hline 8) Depreciação da Empilhadeira & US\$604.17 \\
\hline 9) Depreciação Móveis e Utensílios & US\$67.82 \\
\hline 10) Quantidade Produzida (toneladas de migalhas) & 255.55 \\
\hline 11) Quantidade Produzida (toneladas de frag. de aço) & 68.73 \\
\hline
\end{tabular}

Quadro 3 - Demonstrativo de quantidades e valores mensais envolvidos na Produção.

Para a quantidade de produtos produzidos, mostrados no Quadro 8, foram necessários quarenta e sete mil e setenta e oito pneus de automóveis e um mil cento e sete pneus de caminhões.

No Quadro 4 apresentam-se as receitas obtidas com a venda dos produtos extraídos do pneu e o custo direto rateado pela respectiva produção, ou seja, 78,81\% da matéria-prima são transformadas em migalha, o restante, em aço (computando o nylon e outros resíduos nestes percentuais). 


\begin{tabular}{|l|c|c|}
\hline \multicolumn{1}{|c|}{ Produto } & Receita Mensal (US\$) & Total do Custo Direto \\
\hline Migalha de Borracha & $73,986.83$ & $78,81 \%$ \\
\hline Fragmento de Aço & $7,163.52$ & $21,19 \%$ \\
\hline Total & $81,150.35$ & $100 \%$ \\
\hline
\end{tabular}

Quadro 4 - Demonstrativo do cálculo da receita e do custo direto.

A estrutura de resultado é finalizada com o Quadro 5, demonstrando os valores envolvidos nas despesas operacionais.

\begin{tabular}{|l|c|}
\hline \multicolumn{1}{|c|}{ Despesas } & Valores (US\$) \\
\hline Amortização de Despesas de Legalização & 5.03 \\
\hline Amortização de Despesas de Licenciamento & 41.17 \\
\hline Despesas com Segurança & 52.11 \\
\hline Despesas com comunicação (telefone) & 810.00 \\
\hline Despesas Financeiras & $20,477.80$ \\
\hline Água & 115.00 \\
\hline Energia Elétrica & 65.00 \\
\hline Despesas Com Pessoal Administrativo (c/ encargos) & $2,652.84$ \\
\hline Amortização das Instalações (0,83\% x 259,385.00) & $2,161.54$ \\
\hline Amortização com instaladores & 34.63 \\
\hline Amortização Sistema de Alarme (0,83\% x 332.94) & 2.77 \\
\hline Amortização Registro de Imóveis & 3.57 \\
\hline Amortização Registro da Empresa & 2.26 \\
\hline Despesa com Contador & 177.00 \\
\hline Amortização Terreno & 84.57 \\
\hline Total & $26,685.29$ \\
\hline
\end{tabular}

Quadro 5 - Demonstrativo das despesas operacionais.

As amortizações com legalização, licenciamento, instalações, instaladores e sistema de alarme foram calculados a uma taxa de $10 \%$ ao ano. A despesa com segurança refere-se ao pagamento mensal do monitoramento para a empresa SOS Monitoramento. A comunicação refere-se aos gastos com telefone, fax, Internet, etc. A energia, assim como a água, citada pertence à parte administrativa, incluindo vestiário, refeitório e banheiros. As despesas com o pessoal administrativo (salários e encargos sociais) correspondem à soma dos valores gastos com o auxiliar administrativo, a secretária e o gerente.

A Receita de Vendas, do Demonstrativo do Resultado, apresentado no Quadro 6, refere-se a uma produção líquida de $1.320 \mathrm{~kg} / \mathrm{h}$ de migalha de pneus e $320 \mathrm{~kg} / \mathrm{h}$ de fragmentos de aço. Gerando também $240 \mathrm{~kg} / \mathrm{h}$ de nylon e outros resíduos, sem valor comercial. Este resultado baseiase no descarte médio de $80 \%$ de pneus de automóveis e o restante de outros veículos, buscandose, desta forma, beneficiar este mesmo percentual. Já os custos dos produtos vendidos e as despesas operacionais podem ser vista respectivamente nos Quadros 3 e 5. 


\begin{tabular}{|l|c|}
\hline \multicolumn{1}{|c|}{ Demonstrativo do Resultado do Exercício } & Valores (US\$) \\
\hline 1) Receita de Vendas & $81,150.35$ \\
\hline 2) (-) Custo dos Produtos Vendidos & $(44,721.03)$ \\
\hline 3) = Lucro bruto & $36,429.32$ \\
\hline 4) (-) Despesas Operacionais & $(26,685.29)$ \\
\hline 5) = Lucro Operacional & $9,744.03$ \\
\hline 6) (-) IMPOSTOS (alíquota 10,82\% da Receita) & $(8,780.46)$ \\
\hline 7) = Lucro Líquido & 963.57 \\
\hline
\end{tabular}

Quadro 6 - Demonstrativo de Resultado (média mensal).

A alíquota relativa ao imposto baseia-se no Simples Federal. O valor referente ao lucro líquido é obtido aplicando-se a alíquota de 10,82\% sobre a receita de vendas.

\subsubsection{Estrutura patrimonial}

A estrutura patrimonial da indústria em questão foi levantada com base nos dados obtidos através da organização parâmetro e com diversas pesquisas junto a órgãos públicos e privados. Desta forma, construiu-se um Balanço Patrimonial referente ao fim do primeiro mês de exercício da recicladora (31/01/20x1). Como pode ser visto no Quadro 7.

\begin{tabular}{|c|c|}
\hline 1. ATIVOS & Valores (US\$) \\
\hline 1.1 Ativo Circulante & $481,755.01$ \\
\hline \multicolumn{2}{|l|}{ 1.1.1 Disponibilidade } \\
\hline 1.1.1.1 Caixa & $81,150.35$ \\
\hline 1.1.2 Direitos & 0.00 \\
\hline 1.1.2.1 Clientes Ambientais & 0.00 \\
\hline 1.1.3 Estoques & 0.00 \\
\hline 1.1.4 Juros a Vencer & $397,826.12$ \\
\hline 1.1.5 Encargos Bancários a Vencer & $2,778.54$ \\
\hline \multicolumn{2}{|l|}{ 1.2 Ativo não-circulante } \\
\hline 1.2.1 Ativo Realizável longo Prazo & $1,014,253.56$ \\
\hline 1.2.1.1 Juros a Vencer & $983,689.60$ \\
\hline 1.2.1.1 Encargos Bancários a Vencer & $30,563.96$ \\
\hline 1.3.2 Imobilizado & $2,539,298.73$ \\
\hline 1.3.2.1 Terrenos & $10,148.37$ \\
\hline 1.3.2.2 Amortização Terreno & $(84.57)$ \\
\hline 1.3.2.3 Móveis e Utensílios & $8,138.62$ \\
\hline 1.3.2.4 (-) Deprec. Móveis e Utensílios & $(67.82)$ \\
\hline 1.3.2.5 Empilhadeira & $29,000.00$ \\
\hline 1.3.2.6 (-) Deprec. Empilhadeira & $(604.17)$ \\
\hline 1.3.2.7 Imóveis & $259,385.00$ \\
\hline 1.3.2.8 (-) Deprec. Acum. - Imóveis & $(2,161.54)$ \\
\hline 1.3.2.9 Máquinas e Equipamentos Ambientais & $2,254,000.00$ \\
\hline 1.3.2.10 (-) Deprec. Acum. - Máquinas e Equip. & $(18,783.33)$ \\
\hline 1.3.2.11 Equipamentos de Alarme & 332.94 \\
\hline 1.3.2.12 (-) Deprec. Equipamento de Alarme & $(2.77)$ \\
\hline 1.3.3 Diferido & $10,336.84$ \\
\hline 1.3.3.1 Despesas de Licenciamento & $4,960.00$ \\
\hline 1.3.3.2 (-) Amort. Acum. - Licenciamento & $(41.17)$ \\
\hline 1.3.3.3 Gastos com Legalização & 606.71 \\
\hline 1.3.3.4 (-) Amort. Acum. - Legalização & $(5.03)$ \\
\hline 1.3.3.5 Despesa com Instaladores & $4,156.44$ \\
\hline
\end{tabular}




\begin{tabular}{|l|c|}
\hline 1.3.3.6 (-) Amortização com Instaladores & $(34.63)$ \\
\hline 1.3.3.7 Despesas de Registro de Imóveis & 428.29 \\
\hline 1.3.3.8 (-) Amortização de Registro. De imóveis & $(3.57)$ \\
\hline 1.3.3.9 Despesas com Registro da Empresa & 272.06 \\
\hline 1.3.3.10 (-) Amortização Registro da Empresa & $(2.26)$ \\
\hline TOTAL PASSIVOS & $\mathbf{4 , 0 4 5 , 6 4 6 . 4 4}$ \\
\hline & $\mathbf{6 8 5 , 3 7 3 . 0 5}$ \\
\hline 2.1 Passivo Circulante & 0.00 \\
\hline 2.1.1 Fornecedores & 52.11 \\
\hline 2.1.2 Segurança a Pagar & 810.00 \\
\hline 2.1.3 Telefone a Pagar & 115.00 \\
\hline 2.1.4 Água a Pagar & $15,416.62$ \\
\hline 2.1.5 Energia Total a Pagar & $20,477.80$ \\
\hline 2.1.6 Juros a Pagar & $6,658.33$ \\
\hline 2.1.7 Provisão para reposição de lâminas & $2,836.00$ \\
\hline 2.1.8 Salários a Pagar & $1,988.60$ \\
\hline 2.1.9 Encargos Sociais a Pagar & $8,780.46$ \\
\hline 2.1.10 Impostos a pagar & $1,084.00$ \\
\hline 2.1.11 Pró-Labore a Pagar & 177.00 \\
\hline 2.1.12 Honorários a Pagar & $397,826.12$ \\
\hline 2.1.13 Juros s/ Financiamento & $229,151.01$ \\
\hline 2.1.14 Financiamento Máquinas e Equipamentos & $3,070,881.10$ \\
\hline 2.2 Passivo não-circulante & $983,689.60$ \\
\hline 2.2.1 Juros s/ Financiamento & $2,087,191.50$ \\
\hline 2.2.2 Financiamento Máquinas e Equipamentos & $\mathbf{2 8 9 , 3 9 2 . 2 9}$ \\
\hline 2.3 Patrimônio Líquido & $288,428.72$ \\
\hline 2.3.1 Capital Social & \\
\hline 2.3.2 Lucros ou Prejuízos Acumulado & 963.57 \\
\hline 2.3.3 Lucro Líquido & $\mathbf{4 , 0 4 5 , 6 4 6 . 4 4}$ \\
\hline TOTAL & \\
\hline Quadro 7 - Estrutura de Ativo Passivo & \\
\hline
\end{tabular}

Quadro 7 - Estrutura de Ativo e Passivo (em US\$).

Não existem duplicatas a receber, pois se considerou que as vendas foram realizadas todas à vista. Quanto aos estoques, não foi atribuído valor, uma vez que a matéria-prima é obtida de forma gratuita, não há produtos em elaboração e toda a produção foi vendida. As depreciações e amortizações foram calculadas, através de estudos realizados, de acordo com a vida útil.

A tributação foi calculada pela alíquota de 10,82\%, referente à Tabela do Simples Federal. As máquinas e equipamentos foram financiados através do BNDES/BANCO DO BRASIL (FINAME).

No que concerne à amortização, se dará em 120 meses, tendo seu início um ano após a liberação do montante. Nesse primeiro ano será pago, trimestralmente, apenas os juros, cuja taxa é de $4,35 \%$ ao ano. A diferença entre o valor financiado e o montante final amortizado foi lançada como encargos bancários a vencer.

\section{Conclusão}

A instalação de uma usina recicladora de pneus inservíveis, na cidade de Santa Maria, apresenta-se como uma ótima alternativa em termos ambientais, pois tira de circulação uma grande quantidade de pneus inservíveis, não só da cidade de Santa Maria, mas de cidades da região, que também seriam beneficiadas. 
A proposta para a instalação da empresa é no Distrito Industrial de Santa Maria, onde atuaria com 11 funcionários, sendo um gerente (que pode ser o proprietário), uma secretária, cinco operários e quatro auxiliares.

As informações sobre o maquinário necessário para a reciclagem dos pneus foram obtidas através da empresa Dragon Importação e Exportação, e propiciam a reciclagem em migalhas, do pneu, separando o aço da borracha.

Basicamente, com a reciclagem do pneu usado obtêm-se dois produtos, que são: borracha e aço, ambos picados. O preço de venda da borracha é de US\$289.52 a tonelada, e pode ser vendido para usinas de pavimentação asfáltica, empresas de construção que usam a borracha picada no lugar da brita, entre outras. Já o aço pode ser vendido para siderúrgicas, ou empresas compradoras de sucata, que oferecem o preço médio de US\$104.22 a tonelada do aço picado limpo.

Em condições normais de funcionamento, dentro dos limites estabelecidos é possível reciclar em torno de 48.185 pneus por mês. Considerando que a entrada mensal de pneus novos na região de Santa Maria, gira em torno de 30.000, faz-se necessário entrar em acordo com prefeituras mais distantes ou com algum fabricante de pneus, para obtenção da matéria-prima restante. Através dos dados coletados e dos parâmetros construídos chegou-se à importância de US\$71,406.32 para custos e despesas. A receita ficou em US\$81,150.35 e com base na tributação pelo simples nacional que importou em US\$8,780.46 o lucro liquido ficou US\$963.57.

Apesar do alto custo de implantação dessa empresa, considerando o valor do maquinário, o projeto mostrou-se viável economicamente, isso sem considerar que 30,51\% dos custos e despesas referem-se a depreciações e amortizações. Nesse sentido, apesar do lucro líquido ser baixo, o caixa apresenta valor bastante elevado. Deve-se considerar a possibilidade de uma parceria com algum fabricante de pneus ou com a ANIP, no sentido de prestar o serviço de destruição dos pneus (devido à obrigação que a lei lhes impõe) e dessa forma aumentar as receitas da recicladora.

Com a implantação da usina de reciclagem, a cidade de Santa Maria teria benefícios sociais, econômicos e ambientais, pois traria geração de renda através dos empregos diretos e indiretos, geração de impostos e solucionaria um grande problema, com a destinação ambiental dos pneus, que hoje são lançados a céu aberto, prejudicando o meio ambiente; causando uma imagem negativa da cidade; e ainda prejudicando a saúde de cidadãos, na medida que aumentam as doenças causadas por mosquitos e roedores, vetores, transmissores de doenças, que encontram nos pneus velhos o hábitat ideal para sua proliferação.

Diante dos altos custos de reciclagem de pneus, devem-se buscar máquinas e equipamentos mais baratos, porém com a mesma qualidade de beneficiamento. A busca de isenções de impostos justifica-se uma vez que esta matéria-prima quando pneu novo, já foi tributada. Por ser uma tarefa desta relevância, cumprindo uma função social fundamental, deve obviamente receber todos os incentivos legais por parte do governo.

\section{Referências bibliográficas}

ANDRADE, Hered de Souza. (2007). Pneus inservíveis: alternativas possíveis de utilização. Disponível em <http://www.cse.ufsc.br/gecon/coord mono/2007.1/Hered.pdf>. Acesso em: 04 jun. 2008. 
ANHEMBI, Haroldo A F. Martins. Disponível em: <http://cursos.anhembi.br/uam/disc/tcc_2004/cd/15\%20a\%20utilizacao\%20da\%20borracha.pdf>. Acesso em: 15 abr. 2008.

ANIP - Associação Nacional da Indústria de Pneumáticos. Disponível em:

<http://www.compam.com.br/oquereciclagem.htm>. Acesso em: 28 nov. 2007.

BNDES - Banco Nacional de Desenvolvimento Econômico e social. Finame - Máquinas e Equipamentos. Disponível em: <http://www.bndes.gov.br/linhas/finame.asp>. Acesso em: 29 maio 2008.

COMPAM - Comércio de Papéis e Aparas Mooca Ltda. Disponível em:

<http://www.compam.com.br/oquereciclagem.htm>. Acesso em: 28 nov. 2007.

COMUNICAÇÃO, Assessoria. SMAM realiza coleta de pneus em borracharias do município. Eldorado do Sul. Disponível em < http://www.eldorado.rs.gov.br/noticias/ver noticia.php?r=232> Acesso em: 03 jun. 2008.

DRAGON IMPORT \& EXPORT. Máquinas para Reciclagem de Pneus. Disponível em: <http://www.dragoncomex.com.br/ssk/>. Acesso em: 08 out. 2007.

FEPAM - Fundação Estadual de Proteção Ambiental Henrique Luiz Roessler - RS. Tabelas de Custos. Disponível em: <http://www.fepam.rs.gov.br/licenciamento/area4/14.asp>. Acesso em: 07 maio 2008.

LAKATOS, Eva Maria; MARCONI, Marina de Andrade. Fundamentos de metodologia científica. 6. ed. São Paulo: Atlas, 2005.

MINISTÉRIO DO MEIO AMBIENTE (Brasil). Resolução do Conama № 258. de 26 de Agosto de 1999. Disponível em: <http://www.mma.gov.br/port/conama/legiabre.cfm?codlegi=258>. Acesso em: 30 abr. 2008.

PASSEROTTI, Mayumi. (2003). Reciclagem de Pneus: viabilidade da aplicação de alternativas para utilização de pneus em grande escala. Disponível em < http://www.usp.br/agen/bols/2003/rede1191.htm\#primdestaq >. Acesso em: 09 jun. 2008.

PORTAL BRASIL. Cotações diárias para o mês de "M A R Ç O / 200 8". Disponível em: http://www.portalbrasil.net/2008/economia/dolar riscopais marco.htm. Acesso em: 03 jul. 2008.

RECEITA FEDERAL (Brasil). Anexo II: Partilha do Simples Nacional - Indústria. Disponível em: $<$ http://www.receita.fazenda.gov.br/publico/Legislacao/LeisComplementares/2006/LeiComplementar1232 006Anexo2.doc>. Acesso em: 12 jun. 2008.

SILVA, Antonio Carlos Ribeiro da. Metodologia da pesquisa aplicada à contabilidade. São Paulo: Atlas, 2003.

SUL, Prefeitura São Lourenço. Coleta de pneus prossegue a partir de Terça feira (19). São Lourenço do Sul. Disponível em <http://www.saolourencodosul.rs.gov.br/noticias.php?ID NOTICIA=1817> Acesso em: 03 jun. 2008.

UFRGS, Ensino da Reportagem. Disponível em: <http://www6.ufrgs.br/ensinodareportagem/meiob/asfaltob.html>. Acesso em: 28 mar. 2008. 
UFSM - Universidade Federal de Santa Maria. Disponível em: http://www.ufsm.br. Acesso em 10 abr. 2008.

USP - Universidade de São Paulo. Disponível em:

<http://www.usp.br/agen/bols/2003/rede1191.htm\#primdestaq>. Acesso em: 16 abr. 2008.

VACARIA, Prefeitura. Centro de coleta de pneus velhos. Vacaria. Disponível em <http://www.vacaria.rs.gov.br/vernoticia.php?id=66>. Acesso em: 17 abr. 2008. 